\title{
Underwater endoscopic mucosal resection for a sporadic adenoma located at severe longitudinal ulcer scars in ulcerative colitis
}

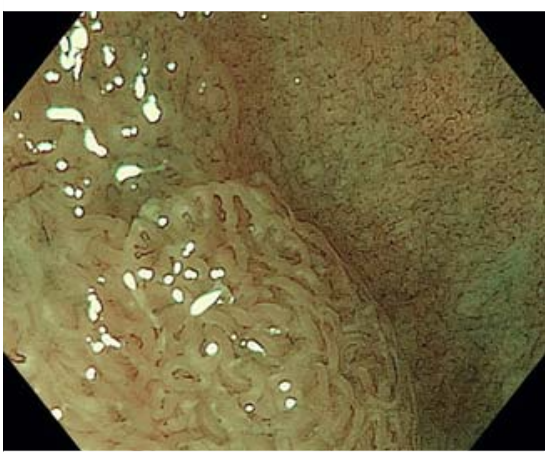

- Fig. 1 Magnifying colonoscopy with narrow band imaging (NBI) showed Japan NBI Expert Team classification type $2 \mathrm{~A}$ with no flat dysplasia lesion in the periphery.

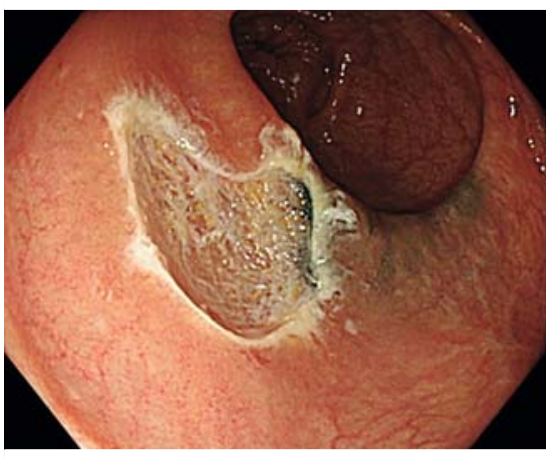

Fig. 4 Underwater endoscopic mucosal resection was completed without any visible neoplastic tissue on the margin of the mucosal defect.

A 52-year-old woman diagnosed with ulcerative colitis (UC) and a history of repeated flare-ups and remissions was referred to our hospital. Colonoscopy revealed a $15-\mathrm{mm}$, flat elevated lesion in the transverse colon. Magnifying colonoscopy with narrow-band imaging (NBI) showed Japan NBI Expert Team classification type $2 \mathrm{~A}$ and no flat dysplasia lesion in the periphery. Pathological findings of the biopsy specimen revealed a partial expression of p53. Based on these findings, we suspected sporadic adenoma ( $>$ Fig. $\mathbf{1}$ ) rather than ulcerative colitis-associated neoplasia. There were

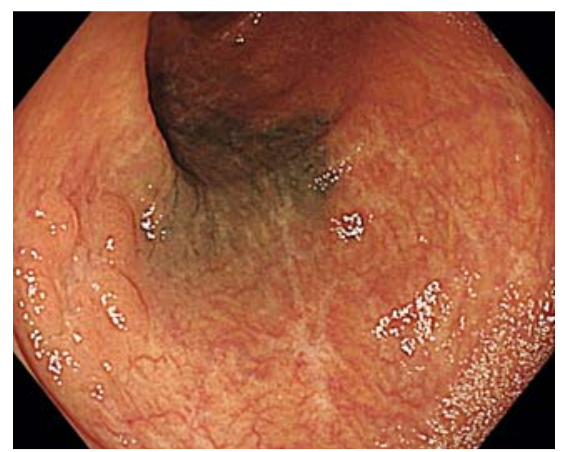

-Fig. 2 Colonoscopy revealed a $15-\mathrm{mm}$, flat elevated lesion in the middle-transverse colon. There were obvious longitudinal ulcer scars from ulcerative colitis inflammation and an endoscopic tattooing scar adjacent to the lesion.

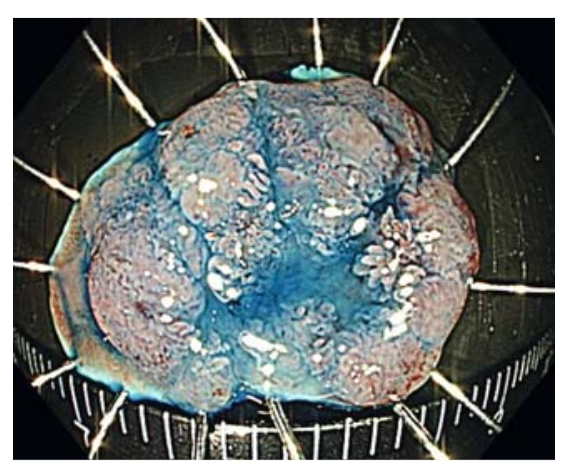

- Fig. 5 Resected specimen after indigo carmine spraying with negative resection margins.

obvious longitudinal ulcer scars as a result of UC inflammation and an endoscopic tattooing scar adjacent to the lesion (> Fig. 2 ).

We decided to carry out underwater endoscopic mucosal resection (UEMR) for this lesion. After full immersion of the target lesion in natural saline, we captured it under $\mathrm{NBI}$ observation using a 20-mm snare (Snare Master; Olympus, Tokyo, Japan) (\$ Fig. 3 ) and removed it. The procedure was completed without any visible neoplastic tissue on the margin of the mucosal defect ( $\triangleright$ Fig.4). En bloc resection without complications

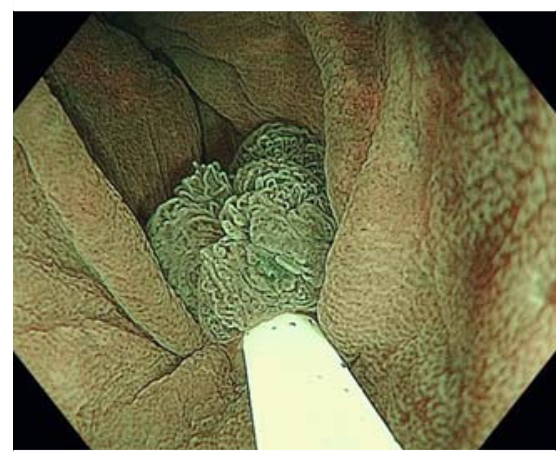

- Fig. 3 The lesion was fully immersed in natural saline, captured with a $20-\mathrm{mm}$ snare, and removed under narrow-band imaging observation.

was achieved ( $>$ Fig. 5, $>$ Video 1 ). Histopathological examination revealed a lowgrade tubular adenoma without tumor involvement on the horizontal and vertical margins.

Conventional endoscopic mucosal resection (EMR) of polyps on severe scars due to UC is technically challenging [1] because submucosal fibrosis from background inflammation makes it difficult to lift the lesion during submucosal injection and to snare the entire tumor. UEMR has been reported to be an effective technique in cases of severe submucosal fibrosis [2-5], but it has not been performed in patients with UC after healing from inflammation. This report presents the first case of successful UEMR of a lesion associated with fibrosis secondary to UC remission and tattooing. UEMR may also be effective in resecting polyps on the fibrous mucosa within the area affected by UC.

Endoscopy_UCTN_Code_TTT_1AQ_2AD

\section{Competing interests}

The authors declare that they have no conflict of interest. 


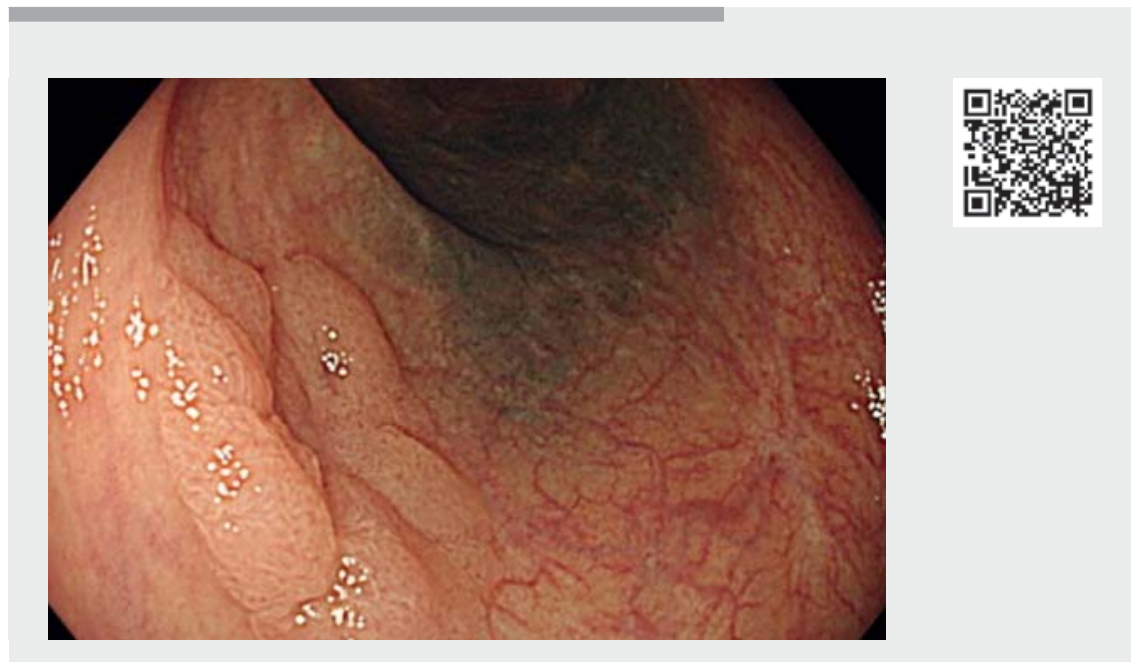

$\checkmark$ Video 1 Underwater endoscopic mucosal resection for a sporadic adenoma located at severe longitudinal ulcer scars in ulcerative colitis.

The authors

Kaoru Takabayashi', Motohiko Kato ${ }^{2,3}$, Motoki Sasaki², Yasushi Iwao ${ }^{3}$, Haruhiko Ogata ${ }^{1}$, Takanori Kanai ${ }^{3}$, Naohisa Yahagi ${ }^{2}$

1 Center for Diagnostic and Therapeutic Endoscopy, School of Medicine, Keio University, Tokyo, Japan

2 Research and Development for Minimally Invasive Treatment, Cancer Center, School of Medicine, Keio University, Tokyo, Japan

3 Division of Gastroenterology and Hepatology Department of Internal Medicine, School of Medicine, Keio University, Tokyo, Japan

\section{Corresponding author}

\section{Kaoru Takabayashi, MD, PhD}

Center for Diagnostic and Therapeutic Endoscopy, School of Medicine, Keio University, 35 Shinanomachi, Shinjuku-ku, Tokyo 160-8582, Japan kaoru0902@yahoo.co.jp

\section{References}

[1] Nishio M, Hirasawa K, Ozeki Y et al. An endoscopic treatment strategy for superficial tumors in patients with ulcerative colitis. J Gastroenterol Hepatol 2020. doi:10.1111/ jgh. 15207

[2] Hosotani K, Imai K, Hotta K et al. Underwater endoscopic mucosal resection for complete $\mathrm{R} 0$ removal of a residual adenoma at a perforated scar in a patient with colostomy. Endoscopy 2017; 49: E121-E122

[3] Takeuchi Y, Tonai Y, Ikeda K. Underwater endoscopic mucosal resection for a superficial polyp located at the anastomosis after surgical colectomy. Dig Endosc 2017; 29: 67-68

[4] Rodrigues JP, Pinho R, Sousa M et al. Underwater endoscopic mucosal resection of a laterally spreading tumor overlying a previous endoscopic carbon tattoo. Endoscopy 2018; 50: E231-E232

[5] Kim HG, Thosani N, Banerjee S et al. Underwater endoscopic mucosal resection for recurrences after previous piecemeal resection of colorectal polyps (with video). Gastrointest Endosc 2014; 80: 1094-1102
Bibliography

Endoscopy 2022; 54: E30-E31

DOI 10.1055/a-1368-3796

ISSN 0013-726X

published online 22.2.2021

(c) 2021. Thieme. All rights reserved.

Georg Thieme Verlag KG, Rüdigerstraße 14 , 70469 Stuttgart, Germany

\section{ENDOSCOPY E-VIDEOS}

https://eref.thieme.de/e-videos

口回 Endoscopy E-Videos is a free Fection, reporting 回: on interesting cases and new techniques in gastroenterological endoscopy. All papers include a high quality video and all contributions are freely accessible online.

This section has its own submission website at https://mc.manuscriptcentral.com/e-videos 